\title{
What do We Know about the Risk Arising from Perfluorinated Compounds
}

\author{
Magdalena Surma $^{1,2 *}$, Henryk Zieliński ${ }^{2}$ \\ 'Malopolska Centre of Food Monitoring, Faculty of Food Technology, University of Agriculture in Kraków, \\ Balicka 122, 30-149 Cracow, Poland \\ ${ }^{2}$ Department of Chemistry and Biodynamics of Food, \\ Institute of Animal Reproduction and Food Research of the Polish Academy of Sciences, \\ Division of Food Science, Tuwima 10, 10-748 Olsztyn, Poland
}

Received: 3 July 2014

Accepted: 23 September 2014

\begin{abstract}
Many studies have shown the adverse effects of perfluorinated compounds (PFCs) on living organisms. PFCs include groups of perfluorinated sulfonic acids, perfluorinated carboxylic acids, fluorotelomer alcohols, high-molecular weight fluoropolymers and low-molecular weight perfluoroalkanamides. These compounds are chemically very stable and are highly resistant to biological degradation. Currently, humans are at increased risk as PFCs are resistant to hydrolysis, photolysis, microbial degradation, or metabolism, and their estimated elimination half-life is about 3.8 years. Therefore, the scale of the bioaccumulation of PFCs in humans is not fully known. Our review provides basic information regarding the chemical nature of PFCs, their production, and use, as well as the current European Union legislation. A special focus was put on the sources of food contamination by PFCs, toxicological studies, estimation of human exposure to PFCs, and tolerable daily intake. At present, there is no legislation for perfluorinated compounds in food of plant and animal origin within the European Union.
\end{abstract}

Keywords: perfluorinated compounds (PFCs), perfluorooctanesulfonate (PFOS), perfluorooctanoic acid (PFOA), sources of emission, occurrence in food, human exposure, risk characterization, tolerable daily intake (TDI)

\section{Chemical Nature of PFCs}

Perfluorinated compounds (PFCs) are a group of organofluorine compounds, aliphatic hydrocarbons, in which all or almost all hydrogen atoms are replaced with fluorine. They consist of a hydrophobic alkyl chain of varying length (typically $\mathrm{C} 4$ to $\mathrm{C} 16$ ), and a hydrophilic end group, X. The hydrophobic part may be fully or partially fluorinated. Their general structure is given in Fig. 1.

The hydrophilic end group, X, can be neutral, or positively or negatively charged. The resulting compounds are

*e-mail: m.surma@ur.krakow.pl

non-ionic, cationic, or anionic surface active agents due to their amphophilic character. PFCs are classified as a persistent and biaccumulative substance [1]. Two dominant PFCs in an environment and food chain are perfluorooctanesulfonate (PFOS, $\mathrm{C}_{8} \mathrm{~F}_{17} \mathrm{SO}_{3}^{-}$) and perfluorooctanoic acid (PFOA, $\mathrm{C}_{7} \mathrm{~F}_{15} \mathrm{COOH}$ ) [2]. They are metabolites of several polyfluorinated precursor compounds that are produced and used commercially. Their general structure is given in Fig. 2. Due to its amphiphilic nature they interfere with the function of the cell membrane, increasing its permeability for non-selective ligands and certain hydrophobic ions [3]. 


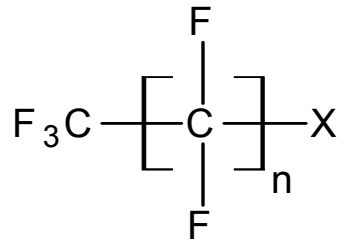

Fig. 1. General structure of perfluorinated alkylated substances.

\section{Production and Use of PFCs, and Current European Union Legislation}

Since the 1950s, thousands of tons of perfluorinated compounds have been manufactured annually, mainly as surfactants and polymers, and have been used in a wide variety of consumer and industrial products due to their unique properties such as excellent thermal and chemical stability, and repellence of both water and oil. Although PFCs were noticed as potential pollutants, they did not draw much attention until 2001, when perfluorooctanesulfonate (PFOS) and perfluorooctanoate (PFOA) were found widespread in human blood and wildlife samples [4,5].

The most-studied PFCs as xenobiotics and also as contaminants in the environment perfluorinated compounds so far are perfluorinated carboxylic acids and perfluorinated: sulfonates, sulfonamides, and telomeric alcohols. In 2000 the annual production of PFOS-related chemicals in the US was estimated to be 3 million $\mathrm{kg}$ [6]. The major producer of polyfluorinated sulfonamidoalcohols in the US, 3M, announced a phasing-out of these products beginning in 2001. Fluorotelomer alcohols (FTOHs) produced via the telomerization process are major raw materials used in various fluoropolymers and fluorosurfactants. These compounds have been shown to degrade to PFOA or other perfluorocarboxylates via atmospheric oxidation reactions or microbial degradation processes [7, 8]. FTOHs are linear, long-chain, polyfluorinated alcohols and are used as intermediates in the synthesis of inks, paints and coatings, polymers, adhesives, waxes, polishes, and caulks (www.dupont.com/zonyl/flash.htm). The global production of PFCs was estimated to be 5-6.5 million $\mathrm{kg} / \mathrm{year}$, of which $40 \%$ occurred in North America [9].

PFOS and PFOA have been used in numerous industrial and commercial applications - including packaging material, cookware and textile treatments, production of fluoropolimers, cosmetics, and in insecticide formulations and firefighting foams - because of their unique properties as synthetic organic chemicals consisting of a fully fluorinated carbon chain and a sulfonate group or carboxylic group, respectively [10]. One of the main applications for the perfluorochemicals in food contact materials is used as starting substances to make polytetrafluoroethylene (PTFE) for non-stick coatings on cookware. There is no evidence for degradability of these compounds at the present time. They decompose only at very high temperatures in specially prepared furnaces.

European Union (EU) Directive 2006/122/EC of the European Parliament and of the Council of 12 December 2006 lays down restrictions on the marketing and use of PFOS for new products in the non-food area which took effect in 2008. This Directive also states that ongoing risk assessment activities for PFOA shall be kept under review. There is currently no legislation for perfluorinated organic substances such as PFOS or PFOA in food or feed within the EU. Their use in plastics and coatings for food contact materials has been approved in The Netherlands and Germany. The European Food Safety Authority (EFSA) Scientific Panel on Food Additives, Flavourings, Processing Aids, and Materials in Contact with Food (AFC) issued an opinion on the safety of ammonium salt of PFOA as a food contact material, but this has not so far led to regulatory measures. Perfluorinated compounds are chemically very stable and are highly resistant to biological degradation. They are dangerous to humans due to their absorption from intestines and accumulation in the target organs, mainly in liver. Currently, humans are at increased risk as PFCs are resistant to hydrolysis, photolysis, microbial degradation, or metabolism, and their estimated elimination half-live is about 3.8 years. Therefore, the scale of the bioaccumulation of PFCs in humans is not fully known. Currently there is a proposal for hazard classification for PFOS in the European Inventory of Existing Commercial Chemical Substances (EINECS). The Conference of the Parties of the Stocholm Convention on Persistent Organic Pollutants (POPs), at its fourth meeting held in May 2009 listed nine additional chemicals as new POPs. PFOS and its salts, as well as perfluorooctane sulfonyl fluoride, are among these new POPs [11]

\section{Sources of Food Contamination by PFCs}

PFOS, PFOA, and perfluorocarboxylic acid (PFCA) are stable degradation products and/or metabolites of neutral PFCs, for example fluorotelomer alcohols (PFTOHs), perfluorinated sulfonamides (PFASAs), and perfluorinated

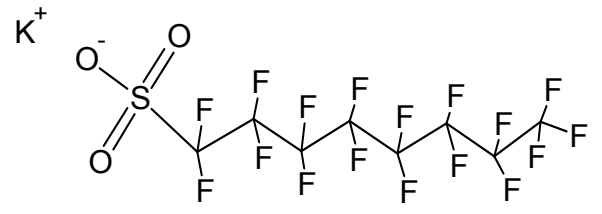

PFOS<smiles>O=C(O)C(F)(F)C(F)(F)C(F)(F)C(F)(F)C(F)(F)C(F)(F)C(F)(F)C(F)(F)F</smiles>

PFOA

Fig. 2. Chemical structure of perfluorooctanesulfonate (PFOS) and perfluorooctanoic acid (PFOA). 
sulfonamide ethanols (PFASEs). Due to their persistency, these compounds are biomagnified in the food chain, leading to increased levels of PFCs in food of animal origin. PFCs tend to accumulate in the food chain and were detected almost ubiquitously, e.g., in water, plants, different kinds of foodstuffs, in animals such as fish, birds, in mammals, as well as in human breast milk and blood in several parts of the world [12]. Bioaccumulation in fish has been shown to be the main source of PFCs in a diet [13]. Food preparation is another source of contamination [14], but preliminary data on the effect of domestic cookware on levels of PFCs attributable to the preparation of food indicated no elevated levels (although in a limited number of experiments) [15]. Greaseproof packaging for convenience foods and special packaging may also introduce PFCs into food via migration [14]. A paper desired for food packaging usually contains coating/additives with PFOS and PFOA for oil and water resistance [3].

\section{Toxicological Studies of PFCs}

The main feature of the "technological" PFCs is their surface activity, and this unique ability to modify the surface properties of other substances, including blood proteins, which is being paid special attention by researchers. At the cellular level, some PFCs can be responsible for the following processes: changes in the transport pathway and bioconversion (metabolism) of lipid substances, impairing transport across cell membranes and slowing down this process, damaging the peroxisome (spherical organelles surrounded by a single membrane) leading to the collapse of the lipid dissociation, induction of enzymes of the cytochrome P450 family and disturbances of oxidation and reduction reactions, or the operation of the oxidative phosphorylation mitochondrion [16-18].

Animal studies show that even very small doses of perfluorinated sulfonates (PFAS) may impair reproductive function (even in further generations) and also adversely affect fetal development, reducing the percentage of live births and reducing the survival of the animals born [1]. There is also evidence on PFAS hepatotoxicity (liver damage), and their interference with the functions of the thyroid hormones and fatty acid metabolism. They may also interfere with intercellular communication and neurohormonal function $[19,20]$.

Two dominant PFCs in food and feed, namely PFOA and PFOS, have been found in the serum, liver, and kidney, but the scale of bioaccumulation depends on their content in food and feed sources. Currently there is a lack of studies on the accumulation of these compounds in the colon, as far as we are concerned. On the other hand, there are available reports that these compounds inhibit the secretion of cytokines in immune cells, with different mechanisms of action [21]. However, the number of works that investigate the effect of these compounds on intestinal amount is relatively scarce.

Of particular concern has been the developmental toxicity of PFOS and PFOA, which has been manifested in rodent studies as high mortality of prenatally exposed new- born rats and mice within $24 \mathrm{~h}$ after delivery. In a study by Lau et al. [22], pregnant Sprague-Dawley rats and CD-1 mice were given $1-20 \mathrm{mg} / \mathrm{kg}$ PFOS/day from gestational day (GD) 2 to GD 20 and GD 1 to GD 17, respectively. At high doses (10 mg/kg/day) an increase was observed in the prevalence of birth defects, such as cleft palate, anasarca, ventricular septal defects, and enlargement of the right atrium. The neonates showed a reduction in both free and bound serum thyroxine (T4) (all groups) and experienced a delay in eye opening ( $2 \mathrm{mg} / \mathrm{kg} /$ day). Even more concerning was the observation that $50 \%$ of the newborn rats and mice died within $24 \mathrm{~h}$ when prenatally exposed to 3 and 10 $\mathrm{mg} / \mathrm{kg} /$ day respectively A study by Luebker et al. [23] showed that maternal exposure to $1.6 \mathrm{mg}$ PFOS/kg/day during pregnancy is a critical dose leading to approximately $50 \%$ mortality among prenatally exposed rat pups within 4 days after delivery [22]. In animal experiments, steep dose response curves were often observed with a narrow dose range between no observed adverse effects and treatment-related death. The nervous system appears to be one of the most sensitive targets of environmental contaminants, which have been suspected as possible causative agents for an increased prevalence of attention deficit hyperactivity disorder (ADHD) and susceptibility of dementia disorders, such as Parkinson's disease [24, 25]. In addition, it has been hypothesized that environmental contaminants can affect cognitive functions such as learning and behavior, and motor skills [26-28]. The levels in brain are, in general, lower than in liver tissue and serum, indicating that most PFCs have limited access to cross the blood brain barrier (BBB). Several studies have, however, shown that PFCs are accumulated in highest concentrations in the liver, indicating a preferential accumulation in this organ, which may be due to a high affinity to proteins [23]. Only one study has compared concentrations of PFCs between the adult and juvenile brain showing a higher relative concentration of PFOS in brain of the rat fetuses compared with the brains from the dams and juveniles with a factor of approximately 10 [2].

Histopathological observation showed that relatively serious damage occurred in the liver and lung, mainly including hepatocytic hypertrophy and cytoplasmic vacuolation in the livers and congestion and thickened epithelial walls in the lungs. PFOA concentrations in main target organs were in the following order: kidney $>$ liver $>$ lung $>$ heart and whole blood $>$ testicle $>$ spleen and brain, whereas the bioaccumulation order for PFOS was liver $>$ heart $>$ kidney $>$ whole blood $>$ lung $>$ testicle, spleen, and brain. The liver, as the predominant accumulation tissue for PFOS, showed corresponding histological changes. There is evidence that some specific proteins in the liver can bind with PFOS, which might contribute to the preferential accumulation of PFOS therein [23]. Slotkin et al. [30] investigated developmental effects of PFOSA (perfluorooctane sulfonamide), PFOS, PFOA, and PFBS (perfluorobutanesulfonate) on PC12 cells in vitro. They showed that particularly PFOSA, but also PFOS, promoted differentiation of the PC12 cell into the cholinergic phenotype at the expense of the dopaminergic phenotype. At the highest concentration, the effect of 
PFOSA switched and promoted differentiation into the dopaminergic phenotype. No mechanisms for the effects were postulated, but it was suggested that the induction of oxidative stress could be a factor. PFOSA induced lipid peroxidation and also was the most cytotoxic compound. The findings that several PFCs may disturb the $\mathrm{Ca}^{2+}$-homeostasis may implicate induction of oxidative stress due to activation of several signalling pathways such as protein kinase C (PKC) [31], phospholipase 2 (PLA2) [32], nitric oxide synthase (NOS) [33], and glutamate receptors [28]. Recent reports have shown that at relatively high concentrations (0.1-100 $\mu \mathrm{g} / \mathrm{mL}$ of culture medium) both PFOA and PFOS interfere with cytokine production by primary cultures of human immune cells, as well as by a human monocytic leukemia cell line [21]. For instance, both of these compounds suppress LPS-induced TNF-alpha (tumor necrosis factor) production by cultures of human peripheral blood leukocyte and by the human promyelocytic THP-1 cell line, but only the effect of PFOA is dependent on PPARa (peroxisome proliferator activated receptors alpha). In addition, both PFOA and PFOS attenuate the phytohemagglutinin (PHA)-induced release of IL-4 (interleukin 4) and IL-10 (interleukin 10) by T cells [21].

Pro-inflammatory effects of PFOS have been observed in several tissues and organs. For example, administration of PFOS to adult rats for 28 days resulted in focal hemorrhage, erythrocytic transudation, and focal hepatocytic degeneration accompanied by inflammatory cellular infiltration in liver [34]. In addition, PFOS exposure resulted in brain injury, including focal hyperplasia of cerebral gliocytes, dilatation, and congestion in inferior caval veins of cerebral arachnoid matter accompanied by slight focal hemorrhage, broadened gap around veins and neurocytes, and focal demyelination of nerve fibers [34]. Short-term exposure of PFOS with higher concentrations in mice increased the expression of inflammatory factors in peritoneal macrophages, such as TNF-alpha and IL-6 (Interleukin 6) [35]. In addition, PFOS exposure enhanced the inflammatory responses of macrophages to lipopolysaccharide and altered the immunological function [35].
Subchronic PFOS exposure for adult male C57BL/6 mice elevated the expression of pro-inflammatory cytokines TNF-alpha, IL-1beta, IL-6, in spleen [34]. Therefore, it is speculated that proinflammatory effects contributed to the developmental neurotoxicological process. PFOS could be absorbed into the human body gastrointestinally, or through the respiratory tract or wounded skin [36]. It can be transported into fetus and infants via maternal placenta and lactation, and can penetrate the blood brain barrier into the brain and produce a neurotoxic effect $[36,37]$. It was shown that PFOS administration could cause long-term accumulation of PFOS in the brain and prenatal PFOS administration caused more accumulation in pup brains than dam brains [2]. It has been reported that the immune system is a sensitive target of PFC toxicity suppressing immunity in mice, resulting in a significant increase in emacitation and mortality in response to influenza A virus [38].

\section{Estimation of Human Exposure to PFCs and Tolerable Daily Intake}

There are a number of pathways by which PFC contamination of humans can take place, including diet, food contact materials, non-food personal items, and indoor and outdoor air (Fig. 3) [39]. There is, however, a general consensus that dietary uptake represents the largest contribution. Humans can be exposed to PFCs through the consumption of contaminated foodstuffs and/or drinking water, as a result of their migration from food packaging, as well as through the lungs and skin of the products that surround us every day. They are well absorbed from the intestines and accumulated primarily in the liver [40]. The presence of strong C-F bonds makes them chemically stable and resistant to hydrolysis, photolysis, microbial degradation, or metabolism [3]. The greatest portion of the chronic exposure to these compounds have been suggested to be the result from the intake of contaminated foods, including drinking water [1]. There are no systematic investigations of the occurrence of PFCs in European food available that could form a basis for a comprehensive dietary exposure

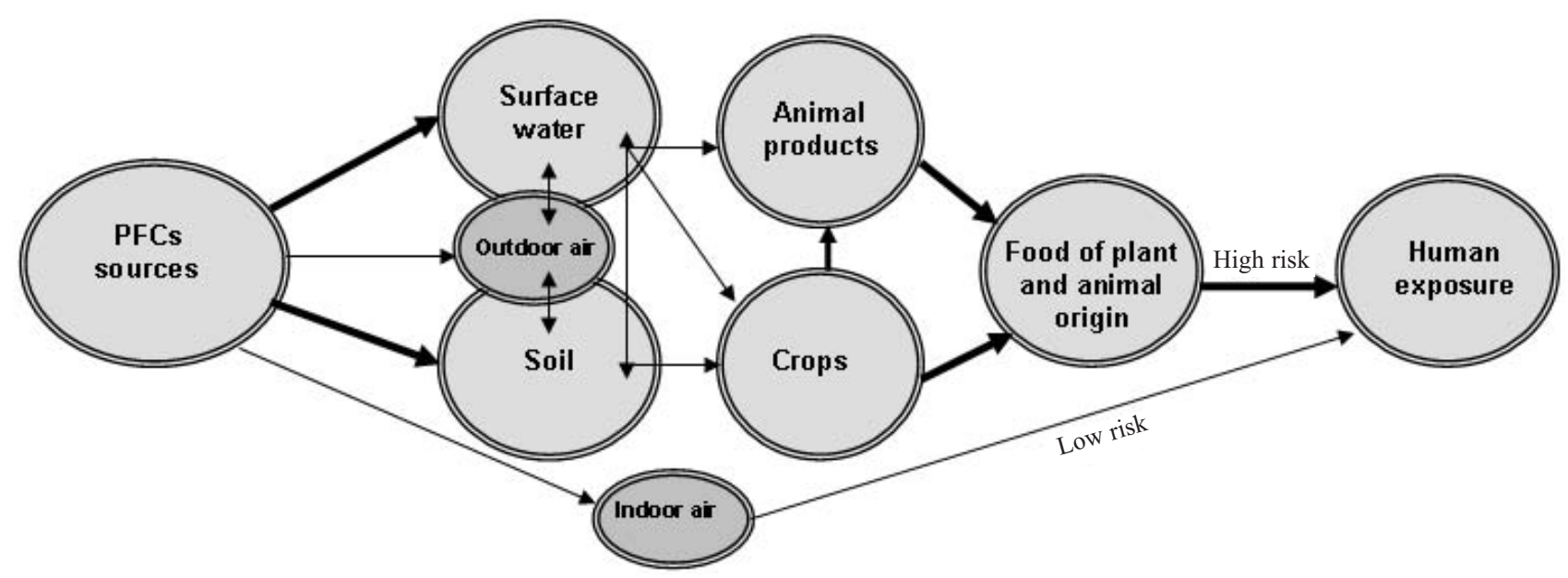

Fig. 3. Sources of PFC emission, environmental contamination, and risk of human exposure. 
assessment. Due to the lack of data, it has not been possible to perform an assessment of the relative contribution from different foodstuffs to human exposure to PFOS and PFOA. Based on the limited information available, fish and fishery products seem to be one important source of human exposure to these compounds. Non-food sources of PFOS were estimated to contribute in the order of $2 \%$ or less of average dietary exposure. Drinking water appears to contribute less than $0.5 \%$. For PFOA at these estimated intakes, non-food sources could contribute up to $50 \%$ of average dietary exposure, whereas drinking water would contribute less than $16 \%$. It has been identified in non-stick coatings and in food contact material such as microwave popcorn bags, but no substantial transfer to food has been demonstrated. PFOS and PFOA are readily absorbed after oral exposure. Biotransformation does not seem to play a relevant role for its elimination. Half-lives in rats, Cynomolgus monkeys and humans are in the region of $>0$ days, 200 days, and 5.4 years, respectively, for PFOS. Estimated elimination half-lives are $<24 \mathrm{~h}$ in female rats, 9 days in male rats, and 21 and 30 days for male and female Cynomolgus monkeys, respectively, and about 3.8 years in humans for PFOA [41]. PFOS and PFOA can cross the blood brain barrier. It can also cross the placenta and thus be transferred to the fetus. PFOS can also be transferred to the offspring via lactation, although the levels recorded in milk are lower than those in the maternal plasma. The PFOS and PFOA blood and tissue levels measured in humans do not necessarily reflect exposure to them from food and non-food sources as there is a number of potentially important precursors that could be transformed into these compounds in the body [41].

The mean PFOA concentration in the blood for the European population is within the region of 4 to $20 \mu \mathrm{g} / \mathrm{L}$; their mean PFOS serum concentration is within the range of $4 \mu \mathrm{g} / \mathrm{L}$ (Italy) and $55 \mu \mathrm{g} / \mathrm{L}$ (Poland) [41]. PFOS is the quantitatively dominant component of PFCs in all of the blood samples measured worldwide. In general, Olsen et al. [36] determined the PFOS concentrations in serum to be 6.1 to $58.3 \mu \mathrm{g} / \mathrm{L}$ and in human liver 4.5-57 $\mu \mathrm{g} / \mathrm{kg} \quad(\mathrm{n}=31)$. Kärrman et al. [42] examined $473 \mathrm{blood} /$ serum/plasma samples from people of various countries. Of the four PFCs measured (PFOS, PFHxS, PFOA, PFOSA), PFOS was quantitatively the dominant component in blood. The highest PFOS concentrations were detected in samples from the USA and Poland ( $>30 \mu \mathrm{g} / \mathrm{L})$. These evidences clearly indicate the higher risk to PFC exposure of Polish populations through the world.

So far as pointing out the available scientific literature, only perfluorooctanesulfonate (PFOS) and perfluorooctanoic acid (PFOA) were the subject of a scientific opinion issued by an expert panel EU Commissioner for contamination in the food chain [41]. The review mentioned above touches the review of experimental data concerning the presence of these compounds in food and the environment, the results of toxicological studies involving animals and the presence of biological effects in the body for the first time. The result of the expertise was the first preliminary estimation of size of the EU population exposure to these compounds and an indication of acceptable daily intake (PFOS TDI $=150 \mathrm{ng} / \mathrm{kg}$ bw/day and PFOA TDI=1.5 $\mu \mathrm{g} / \mathrm{kg}$ bw/day). The conclusions from studies on animals (mice, rats, and monkeys) and varied PFOS and PFOA administration into the body (orally, in capsules, by injection, and by the consumption of feed), based on the estimated dose of these compounds (at which there were no adverse changes in the body of experimental animals, or NOAEL-noobserved-adverse-effect-level) were the basis for the TDI indication. The lowest NOAEL for PFOS identified, 0.03 $\mathrm{mg} / \mathrm{kg} \mathrm{b.w.} \mathrm{per} \mathrm{day,} \mathrm{originates} \mathrm{from} \mathrm{a} \mathrm{subchronic} \mathrm{study} \mathrm{with}$ Cynomolgus monkeys showing changes in lipids and thyroid hormones at the next higher dose of $0.15 \mathrm{mg} / \mathrm{kg}$ b.w. per day. The Scientific Panel on Contaminants in the Food Chain (CONTAM) considered these biochemical changes observed at this dose level to be treatment-related and therefore concluded that $0.03 \mathrm{mg} / \mathrm{kg}$ b.w. per day should be used as the NOAEL in the assessment. The lowest NOAEL for PFOA identified was $0.06 \mathrm{mg} / \mathrm{kg}$ per day in a subchronic study in male rats. At the next higher dose $(0.64$ $\mathrm{mg} / \mathrm{kg}$ b.w.), hepatocellular hypertrophy and increased liver weight was seen. It should be noted that the kinetic properties of PFOA in rats as well as humans are not well understood. The striking difference between male and female rats, as given by the much shorter half-lives for females, indicates that studies on female rats on reproduction and offspring development should be interpreted with care [41]. Showing the lowest level was to identify those compounds, which have observed any changes in their body (LOAELlowest-observed-adverse-effect-level) was an another important parameter resulting from experimental studies on animals, depending on the method and time of exposure to PFOS and PFOA, the type of animal and their sex, and halflife in the body [43].

\section{Methods of PFC Determination}

Because of the emerging relevance of PFCs in food safety there is a extreme need for their determination. The major problems encountered in analysis of PFCs are contamination of blanks and samples during the analytical process [44], because of contact with laboratory material containing fluoropolymers, losses associated with adsorption of PFCs on sample containers (for example glass or polymeric container surfaces), and possible losses because of biodegradation and biotransformation.

For extraction of complex matrices, for example food, procedures based on ion-pair extraction have been widely used, although sometimes these suffer from matrix effects. Tetra-n-butylammonium hydrogen sulfate solution and sodium carbonate buffer at $\mathrm{pH} 10$ is used as the ion-pairing agent and methyl tert-butyl ether (MTBE) as the extractant [45, 46]. Liquid-solid extraction (LSE) also has been applied, and target compounds are extracted by soaking the sample in methanol and shaking [15]. After clean-up with active carbon the extract is ready for analysis. This approach does not suffer from matrix effects, and recoveries are usually high, ranging from 80 to $110 \%$. Several stud- 
ies have been performed using $\mathrm{KOH}$ digestion followed by solid-phase extraction (SPE) $[47,48]$ or filtration followed by SPE. Because of the different polarities of PFCs, different SPE cartridges have been evaluated. The widely used Oasis WAX cartridges yield good recoveries for short-chain (C4-C6) PFCs whereas less polar phases (C18 and Oasis HLB) may be used for longer chain PFCs. When an ionpairing agent that reduces the polarity of the ion-pair complex is used, a non-polar solvent (e.g. MTBE) may be used. Non-ionic PFCs may be extracted from the matrix by nonpolar media (C18 SPE or hexane), although moderately polar media (Oasis HLB and Oasis WAX, hexane-acetone mixtures or acetonitrile) also have been used.

Nowadays, QuEChERS (quick, easy, cheap, effective, rugged, and safe) methodology is a frequent, attractive option for sample preparation in food analysis. The QuEChERS method is particularly popular for the determination of polar, middle polar, and nonpolar pesticide residues in food matrices [49, 50], although this methodology is also being used for the analysis of other families of compounds [51-53]. It was originally developed by Anastassiades et al. [54] for determination of a wide range of pesticide residues in fruits and vegetables and then modified by Lehotay et al. for analysis of fatty matrices $[55,56]$.

The analytical chemistry of PFAS and related compounds has recently been reviewed by de Voogt and Sáez [57]. Analytical methods for the determination of organic fluorine were initially based on converting organic fluorine to soluble fluoride [58]. Gas chromatography (GC) can be used for the direct determination of the neutral, volatile perand poly-fluorinated alkylated substances, including several precursors of PFOS and PFOA, e.g., the sulfonamides, fluorotelomer alcohols [59], and olefins. These compounds have high vapour pressures (typically up to several hundreds of Pa). The perfluorinated alkanoic acids cannot be determined directly and need to be derivatised in order to be amenable to GC analysis [60]. Derivatization reaction yields can be non-reproducible, but PFOS has a very low vapour pressure and its derivatives are unstable [61]. Liquid chromatography (LC) has been used with several conventional detectors for the separation of PFAS. These include conductimetric [62] and fluorescence detection (LC-FLU). The latter can only be employed after derivatisation (e.g. with 3-bromoacetyl-7-methoxycoumarin) because of the general absence of fluorophores in PFAS. The development of LC - electrospray ionisation (ESI) mass spectrometry (MS), and LC tandem MS has enabled substantial improvements of the analytical chemistry of the PFAS. LC-MS and in particular LC-MS/MS can be considered the current standard for analysis of anionic perfluorinated surfactants. LC with single quadrupole MS, though a sensitive technique, requires more thorough clean up of the sample in order to remove interferences, because of its inherent lower selectivity. The majority of reports in the literature employed LC-ESIMS/MS as the analytical method. Currently quadrupole-time-of-flight (Q-TOF) MS analyzers have a lower sensitivity than triple quadrupole MS/MS systems, but seem to be suitable instruments for the identification of perflurinated acrylated substances (PFAS) in the environment [63]. Berger et al. [64] compared three different mass spectrometric techniques coupled to LC with ion trap MS, triple quadrupole MS, and high resolution TOF. For all instruments ESI was the best suited interface for analysis of PFAS. Ion trap MS was best suited for qualitative purposes and identification of branched isomers. Triple quadrupole MS-MS appeared to be the method of choice for quantitative analysis of telomer alcohols, having a limit of detection (LOD) in the low picogram range, and with typical detection limits for other PFAS of 10 to $100 \mathrm{pg}$. TOF-MS appeared to be the optimum quantitative method for PFAS, combining high selectivity with high sensitivity (2 to $10 \mathrm{pg}$ ).

LC-MS-MS using a triple-quadrupole mass spectrometer (QqQ) operating in multiple reaction monitoring (MRM) mode is one of the most widely applied techniques, and one of the most suitable for quantification of PFCs. Nowadays, ion trap (IT) and time of flight (TOF) detectors are also used for trace quantification of PFCs. Because PFCs contain carboxyl, sulfonic, hydroxyl, or sulfonamide groups, which have acidic properties and can therefore dissociate, electrospray ionization in the negative mode (ESI(-)) is best suited to analysis of PFCs in food and feed samples [65].

\section{Conclusions}

Perfluorinated compounds (PFCs) are synthetic xenobiotics. Among them, perfluorooctanesulfonate (PFOS) and perfluorooctanoic acid (PFOA) are two highly persistent members of the group of perfluorinated alkylated substances (PFAS). Nowadays many PFOS and PFOA-related compounds are commercially produced and used in a vast number of applications in relatively large amounts. These compounds are today widely distributed in the environment and PFOS are generally the dominating member of the PFAS family. They are able to bio-accumulate and slowly eliminate from an organism. The critical effects of PFOS and PFOA are effects on the liver including hypertrophy, changes in enzyme activities, and increases in absolute or relative liver weight, but developmental effects also have been observed in experimental animals.

Currently there are no regulations defining the permissible content of perfluorinated compounds for food, water, and solid matter suspended in the air in the EU, despite the fact that their presence has been confirmed in the blood plasma of EU inhabitants as well as working people at increased exposure risk. There is scarce information on human exposure to PFOS and PFOA as well as the number of potentially important precursors that could be transformed into these compounds in the body. Therefore, the occurrence in food and feed and the rate of transformation in the body needs to be assesed as urgently as possible as health effects of perfluorinated compounds (PFCs) in humans still remain controversial [21]. It seems to be that the risk for human arising from PFC exposure will be of increasing concern due to the estimated elimination halflives of PFOS and PFOA (about 3.8 years in humans). 
Finally, further data on PFAS levels in food and in humans would be desirable, particularly with respect to monitoring trends in exposure.

\section{Acknowledgements}

This article was supported by Project REFRESH (FP7REGPOT-2010-1-264105) - Unlocking the potential of the Institute of Animal Reproduction and Food Research for strengthening integration with the European Research Area and region development. Project financed in the area of "Research Potential" of the $7^{\text {th }}$ Framework Program.

\section{References}

1. JOGSTEN I.E., PERELLO G., LLEBARIA X., BIGAS E., MARTI-CID R., KARRMAN A., DOMINGO J.L. Exposure to perfluorinated compounds in Catalonia, Spain, through consumption of various raw and cooked foodstuffs, including packaged food. Food Chem. Toxicol., 47, (7), 1577, 2009.

2. YEUNG L.W.Y., TANIYASU S., KANNAN K., XU D.Z.Y., GURUGE K.S., LAM P.K.S, YAMASHITA N. An analytical method for the determination of perfluorinated compounds in whole blood using acetonitrile and solid phase extraction methods. J. Chromatogr. A, 1216, (25), 4950, 2009.

3. POOTHONG S., BOONTANON S.K., BOONTANON N. Determination of perfluorooctane sulfonate and perfluorooctanoic acid in food packaging using liquid chromatography coupled with tandem mass spectrometry. J. Hazard. Mater., 205-206, 139, 2012.

4. HANSEN K.J., CLEMEN L.A., ELLEFSON M.E., JOHNSON H.O. Compound-specific quantitative characterization of organic fluorochemicals in biological matrices. Environ. Sci. Technol., 35, (4), 766, 2001.

5. GIESY J.P., KANNAN K. Global distribution of perfluorooctane sulfonate in wildlife. Environ. Sci. Technol., 35, (7), 1339, 2001.

6. US EPA, Perfluorooctyl sulfonates: proposed significant new use rule. Federal Register, 65, 62319, 2000.

7. DINGLASAN M.J.A., YE Y., EDWARDS E.A., MABURY S.A. Fluorotelomer alcohol biodegradation yields poly- and perfluorinated acids. Environ. Sci. Technol., 38, (10), 2857, 2004.

8. ELLIS D.A., MARTIN J.W., DE SILVA A.O, MABURY S.A., HURLEY M.D., ANDERSEN M.P.S., WALLINGTON T.J. Degradation of fluorotelomer alcohols: a likely atmospheric source of perfluorinated carboxylic acids. Environ. Sci. Technol., 38, (12), 3316, 2004.

9. U.S. EPA (United States Environmental Protection Agency). Preliminary risk assessment of the developmental toxicity associated with exposure to perfluorooctanoic acid and its salts. U.S. Environmental Protection Agency, Office of Pollution Preventionand Toxics, Risk Assessment Division, April 10, 2003. Washington DC, USA.

10. DOLMAN S., PELZING M. An optimized method for the determination of perfluorooctanoic acid, perfluorooctane sulfonate and other perfluorochemicals in different matrices using liquid chromatography/ion-trap mass spectrometry. J. Chromatogr. B., 879, (22), 2043, 2011.
11. SEACAT A.M., THOMFORD P.J., HANSEN K.J., CLEMEN L.A., ELDRIDGE S.R., ELCOMBE C.R., BUTENHOFF J.L. Sub-chronic dietary toxicity of potassium perfluorooctanesulfonate in rats. Toxicology, 183, (1-3), 117, 2003.

12. GIESY J.P., KANNAN K. Global distribution of perfluorooctane sulfonate in wildlife. Environ. Sci. Technol., 35, (7), 1339, 2001.

13. LLORCA M., FARRÉ M., PICÓ Y., BARCELÓ D. Development and validation of a pressurized liquid extraction liquid chromatography-tandem mass spectrometry method for perfluorinated compounds determination in fish. J. Chromatogr. A, 1216, (43), 7195, 2009.

14. TITTLEMER S.A., PEPPER K., SEYMOUR C., MOISEY J., BRONSON R., CAO X.L., DABEKA R.W. Dietary exposure of Canadians to perfluorinated carboxylates and perfluorooctane sulfonate via consumption of meat, fish, fast foods, and food items prepared in their packaging. J. Agric. Food Chem., 55, (8), 3203, 2007.

15. POWLEY C.R., GEORGE S.W., RYAN T.W., BUCK R.C. Matrix effect-free analytical methods for determination of perfluorinated carboxylic acids in environmental matrixes. Anal. Chem., 77, (19), 6353, 2005.

16. LEHMLER H.-J. Synthesis of environmentally relevant fluorinated surfactants - a review. Chemosphere, 58, (11), 1471, 2005.

17. DINGLASAN-PANLILIO M.J., MABURY S.A. Significant residual fluorinated alcohols present in various fluorinated materials. Environ. Sci. Technol., 10, 1447, 2006.

18. HU W., JONES P.D., CELIUS T., GIESY J.P. Identification of genes responsive to PFOS using gene expression profiling. Environ. Toxycol. Parmacol., 19, (1), 57, 2005.

19. AUSTIN M.E., KASTUTI B.S., BARBER M., KANAN K., MOHANKUMAR P.S.J. Neuroendocrine effects of perfluorooctane sulfonate in rats. Environ. Health Perspect., 111, (12), 1485, 2003

20. HU W., JONES P.D., UPHAM B.L., TROSKO J.E., LAU C., GIESY J.P. Inhibition of gap junctional intercellular communication by perfluorinated compounds in rat liver and dolphin kidney epithelial cell lines in vitro and Sprague-Dawley rats in vivo. Toxic. Sci., 68, (2), 429, 2002.

21. CORSINI E., AVOGADRO A., GALBIATI V., DELL'AGLI M., MARINOVICH M., GALLI C.L., GERMOLEC D.R. In vitro evaluation of the immunotoxic potential of perfluorinated compounds (PFCs). Toxicol. Appl. Pharmacol., 250, (2), 108, 2011.

22. LAU C., THIBODEAUX R.J., HANSON R.G., ROGERS J.M., GREY B.E. Exposure to perfluorooctane sulfonate during pregnancy in rat and mouse. II: Postnatal evaluation. Toxicol. Sci., 74, 382, 2003.

23. LUEBKER D.J., CASE M.T., YORK R.G., MOORE J.A., HANSEN K.J., BUTENHOFF J.L. Two-generation reproduction and cross-foster studies of perfluorooctanesulfonate (PFOS) in rats. Toxicology, 215, (1-2), 126, 2005.

24. HOFFMAN K., WEBSTER T.F., WEISSKOPF M.G., WEINBERG J., VIEIRA V.M. Exposure to Polyfluoroalkyl Chemicals and Attention Deficit/Hyperactivity Disorder in U.S. Children 12-15 Years of Age. Environ. Health Perspect., 118, (12), 1762, 2010.

25. BROWN R.C., LOCKWOOD A.H., SONAWANE B.R. Neurodegenerative diseases: an overview of environmental risk factors. Environ. Health Perspect., 113, (9), 1250, 2005. 
26. FONNUM F., MARIUSSEN E. Mechanisms involved in the neurotoxic effects of environmental toxicants such as polychlorinated biphenyls and brominated flame retardants. J. Neurochem., 111, (6), 1327, 2009.

27. GRANDJEAN P., LANDRIGAN P.J. Developmental neurotoxicity of industrial chemicals. Lancet, 368, (9553), 2167, 2006.

28. MARIUSSEN E., FONNUM F. Neurochemical targets and behavioral effects of organohalogen compounds: an update. Crit Rev Toxicol, 36, (3), 253, 2006.

29. CHANG S.-C., EHRESMAN D.J., BJORK J.A., WALLACE K.B., PARKER G.A., STUMP D.G., BUTENHOFF J.L. Gestational and lactational exposure to potassium perfluorooctanesulfonate $(\mathrm{K}+\mathrm{PFOS})$ in rats: Toxicokinetics, thyroid hormone status, and related gene expression. Reprod. Toxicol., 27, (3-4), 387, 2009.

30. SLOTKIN T.A., MACKILLOP E.A., MELNICK R.L., THAYER K.A., SEIDLER F.J. Developmental neurotoxicity of perfluorinated chemicals modeled in vitro. Environ. Health Perspect., 116, (6), 716, 2008.

31. KODAVANTI P.R.S., SHAFER T.J., WARD T.R., MUNDY W.R., FREUDENRICH T., HARRY G.J., TILSON H.A Differential effects of polychlorinated biphenyl congeners on phosphoinositide hydrolysis and protein kinase $\mathrm{C}$ translocation in rat cerebellar granule cells. Brain Res., 662, (1-2), 75, 1994.

32. KODAVANTI P.R.S., DERR-YELLIN E.C., Differential effects of polybrominated diphenyl ethers and polychlorinated biphenyls on $[3 \mathrm{H}]$ arachidonic acid release in rat cerebellar granule neurons. Toxicol. Sci., 68, 451, 2002.

33. KANG J.-H., JEONG W., PARK Y., LEE S.Y., CHUNG M.W., LIM H.-K., PARK I.-S., CHOI K.H., CHUNG S.Y., KIM D.S., PARK C.-S., HWANG O., KIM J. Aroclor 1254induced cytotoxicity in catecholaminergic CATH.a cells related to the inhibition of NO production. Toxicology, 177, (2-3), 157, 2002.

34. ZENG H., ZHANG L., LI Y., WANG Y., XIA W., LIN Y., WEI J., XU S. Inflammation-like glial response in rat brain induced by prenatal PFOS exposure. NeuroToxicology, 32, 130, 2011

35. QAZI M.R., BOGDANSKA J., BUTENHOFF J.L., NELSON B.D., DEPIERRE J.W., ABEDI-VALUGERDI M. High-dose, short-term exposure of mice to perfluorooctanesulfonate (PFOS) or perfluorooctanoate (PFOA) affects the number of circulating neutrophils differently, but enhances the inflammatory responses of macrophages to lipopolysaccharide (LPS) in a similar fashion. Toxicology, 262, (3), 207, 2009.

36. OLSEN G.W., HUANG H.Y., HELZLSOUER K.J., HANSEN K.J., BUTENHOFF J.L., MANDEL J.H. Historical comparison of perfluorooctanesulfonate, perfluorooctanoate and other fluorochemicals in human blood. Environ. Health Perspect., 113, (5), 539, 2005.

37. APELBERG B.J., WITTER F.R., HERBSTMAN J.B., CALAFAT A.M., HALDEN R.U., NEEDHAM L.L., GOLDMAN L.R. Cord serum concentrations of perfluorooctane sulfonate (PFOS) and perfluorooctanoate (PFOA) in relation to weight and size at birth. Environ. Health Perspect., 115, 1670, 2007.

38. GURUGE K.S., HIKONO H., SHIMADA N., MURAKAMI K., HASEGAWA J., YEUNG L.W., YAMANAKA N., YAMASHITA N. Effect of perfluorooctane sulfonate (PFOS) on influenza A virus-induced mortality in female B6C3F1 mice. J. Toxicol. Sci., 34, (6), $687,2009$.
39. STAHL T., MATTERN D., BRUNN H. Toxicology of perfluorinated compounds. Environmental Sciences Europe, 23, (38), 1, 2011.

40. LOCCISANO A.E., CAMPBELL J.L. JR, BUTENHOFF J.L., ANDERSEN M.E., CLEWELL H.J. Comparison and evaluation of pharmacokinetics of PFOA and PFOS in the adult rat using a physiologically based pharmacokinetic model. Reprod. Toxicol., 33, (4), 452, 2012.

41. EUROPEAN FOOD SAFETY AUTHORITY, Perfluorooctane sulfonate (PFOS), perfluorooctanoic acid (PFOA) and their salts. Scientific opinion of the panel on contaminants in the food chain. EFSA J., 653, 1, 2008

42. KÄRRMAN A., LANGLOIS I., VAN BAVEL B., LINDSTRÖM G., OEHME M. Identification and pattern of perfluorooctane sulfonate (PFOS) isomers in human serum and plasma. Environ. Int., 33, 782, 2007.

43. REAGAN-SHAW S., NIHAL M., AHMAD N. Dose translation from animal to human studies revisited. The FASEB Journal, 22, 659, 2007.

44. TANIYASU S., KANNAN K., SO M.K., GULKOWSKA A., SINCLAIR E., OKAZAWA T., YAMASHITA N. Analysis of fluorotelomer alcohols, fluorotelomer acids, and short- and long-chain perfluorinated acids in water and biota. J. Chromatogr. A, 1093, (1-2), 89, 2005.

45. TANIYASU S., KANNAN K., HORII Y., HANARI N., YAMASHITA N. A survey of perfluorooctane sulfonate and related perfluorinated organic compounds in water, fish, birds, and humans from Japan. Environ. Sci. Technol., 37, 2634, 2003.

46. GURUGE K.S., MANAGE P.M., YAMANAKA N., MIYAZAKI S., TANIYASU S., YAMASHITA N. Speciesspecific concentrations of perfluoroalkyl contaminants in farm and pet animals in Japan. Chemosphere, 73, (1), S210, 2008.

47. YAMASHITAN., KANNAN K., TANIYASU S., HORII Y., OKAZAWA T., PETRICK G., GAMO T. Analysis of perfluorinated acids at parts-per-quadrillion levels in seawater using Liquid Chromatography-Tandem Mass Spectrometry. Environ. Sci. Technol., 38, (21), 5522, 2004.

48. SO M.K., TANYASU S., LAM P.K.S., ZHENG G.J., GIESY J.P., YAMASHITA N. Alkaline digestion and solid phase extraction method for perfluorinated compounds in mussels and oysters from south China and Japan. Arch. Environ. Contam. Toxicol., 50, 240, 2006.

49. GALLART-AYALA H., NUNEZ O., LUCCI P. Recent advances in LC-MS analysis of food-packaging contaminants. Trends in Analytical Chemistry, 42, 99, 2013.

50. CIEŚLIK E., SADOWISKA-ROCIEK A., MOLINA RUIZ J.M., SURMA-ZADORA M., Evaluation of QuEChERS method for the determination of organochlorine pesticide residues in selected groups of fruits. Food Chemistry, 125, (2), 773, 2011.

51. SADOWSKA-ROCIEK A., SURMA M., CIEŚLIK E. Application of QuEChERS Method for Simultaneous Determination of Pesticide Residues and PAHs in Fresh Herbs. B. Environ. Contam. Tox., 90, (4), 508, 2013.

52. SADOWSKA-ROCIEK A., SURMA M., CIEŚLIK E. Comparison of different modifications on QuEChERS sample preparation method for PAHs determination in black, green, red and white tea. Environ. Sci. Pollut. R., 21, 1326, 2013.

53. SURMA M., SADOWSKA-ROCIEK A., CIEŚLIK E. The application of d-SPE in the QuEChERS method for the determination of PAHs in food of animal origin with GC-MS detection. Europ. Food Res. Technol., 238, (6), 1029, 2014. 
54. ANASTASSIADES M., MAŠTOVSKÁ K., LEHOTAY S.J. Evaluation of analyte protectants to improve gas chromatographic analysis of pesticides. J Chromatogr A, 1015, 163, 2003.

55. LEHOTAY S.J. QuEChERS sample preparation approach for mass spectrometric analysis of pesticide residues in foods. Methods Mol Biol., 747, 65, 2011.

56. SURMA M.K., SADOWSKA-ROCIEK A., CIEŚLIK E. Evaluation of the QuEChERS Method with GC-MS Detection for the Determination of Organochlorine Pesticides in Food of Animal Origin. Food Annal. Methods, 7, (2), 366, 2014.

57. DE VOOGT P., SÁEZ M. Analytical chemistry of perfluoroalkylated substances. Trends in Analytical Chemistry, 25, (4), 326, 2009

58. KISSA E. Determination of organofluorine in air. Environ. Sci. Technol., 20, 1254, 1986.

59. MARTIN J.W., MUIR D.C.G, KWAN W.C., MODDY C.A., SOLOMON K.R., MABURY S.A. Collection of airborne fluorinated organics and analysis by Gas Chromatography-Chemical Ionisation-Mass Spectrometry. Anal. Chem., 74, 584, 2002.

60. YLINEN M., KOJO A., HANHIJARVI H., PEURA P. Disposition of perfluorooctanoic acid in the rat after single and subchronic administration. B. Environ. Contam. Tox., 44, 46, 1990 .

61. HEKSTER F.M., P. DE VOOGT A.M., PIJINENBURG C.M., LAANE R.W.P.M. Perfluoroalkylated substances aquatic environmental assessment. Report RIKZ/2002.043. Prepared at the University of Amsterdam and RIKZ (The State Institutefor Coast and Sea), 99, July 1, 2002.

62. HORI H., HAYAKAWA E., YAMASHITA N., TANIYASU S., NAKATA F., KOBAYASHI Y. Highperformance liquid chromatography with conductimetric detection of perfluorocarboxylic acids and perfluorosulfonates. Chemosphere, 57, 273, 2004.

63. HANSEN K.J., CLEMEN L.A., ELLEFSON M.E., JOHNSON H.O. Compound-specific, quantitative characterisation of organic fluorochemicals in biological matrices. Environ. Sci. Technol., 35, 766, 2001.

64. BERGER U., LANGLOIS I., OEHME M., KALLENBORN R. Comparison of three types of mass spectrometers for HPLC/MS analysis of perfluoroalkylated substances and fluorotelomer alcohols. Eur. J. Mass Spectrom., 10, 579, 2004.

65. KANTIANI L., LLORCA M., SNCHIS J., FARRE M., BARCELO D. Emerging food contaminants: a review. Anal Bioanal Chem., 398, 2413, 2010. 
